\title{
Comparative study of transvaginal ultrasonography and CA 125 in the preoperative evaluation of myometrial invasion in endometrial carcinoma
}

\author{
J. L. Alcázar, M. Jurado and G. López-García
}

Department of Obstetrics and Gynecology, Clínica Universitaria de Navarra, School of Medicine, University of Navarra, Pamplona, Spain

Key words: TRANSVAGINAL ULTRASOUND, CA 125, MYOMETRIAL INVASION, ENDOMETRIAL CANCER

\begin{abstract}
Objective To compare the ability of transvaginal sonography and serum CA 125 levels to predict myometrial invasion in patients with endometrial carcinoma.

Design and methods Prospective study in 50 consecutive patients (mean age 60 years, SD 10.5, range 29-77 years) diagnosed as having endometrial cancer and scheduled for surgical staging. All patients were evaluated by transvaginal ultrasonography. Endometrial thickness was measured in all cases and myometrial invasion was estimated as $<50 \%$ or $\geq 50 \%$. Serum CA 125 level was determined in each patient. A cut-off level of $\geq 35 \mathrm{IU} / \mathrm{ml}$ was considered to predict myometrial invasion of $\geq 50 \%$. All patients underwent surgical staging, and definitive histopathological findings regarding myometrial invasion were used as the 'gold standard'. Sensitivity, specificity and positive predictive value (PPV) and negative predictive value (NPV) were calculated for transvaginal ultrasonography and $C A$ 125 and compared.
\end{abstract}

Results On histopathological analysis, myometrial invasion was found to be $<50 \%$ in $35(70 \%)$ cases and $\geq 50 \%$ in 15 cases (30\%). Mean endometrial thickness in patients with superficial invasion was significantly lower than in those with deep invasion (13.4 mm (95\% CI 11.2-15.7) vs. $18.7 \mathrm{~mm}$ (95\% CI 15.0-22.3), respectively; $\mathrm{p}=0.014)$. Median CA 125 was significantly higher in patients with deep invasion than in those with superficial invasion (30 IU/ml, interquartile range (IQR) $46.0 \mathrm{vs.} 16.9 \mathrm{IU} / \mathrm{ml}$, $I Q R$ 13.9, respectively; $\mathrm{p}=0.002)$. The sensitivity, specificity, PPV and NPV for transvaginal ultrasonography were $86.7 \%$ (95\% CI 59.5-98.3), 94.3\% (95\% CI 80.8-99.3), $86.7 \% \quad(95 \%$ CI $59.5-98.3)$ and $94.3 \% \quad(95 \% \quad C I$ 80.8-99.3), respectively. The sensitivity, specificity, PPV and NPV for CA 125 were 40\% (95\% CI 16.3-67.7), 91.4\% (95\% CI 76.9-98.2), 66.7\% (95\% CI 29.9-92.5) and $78 \%$ (95\% CI 63.4-89.5), respectively. The sensitivity of transvaginal ultrasonography was significantly higher than that of CA 125 ( $\mathrm{p}=0.008)$. No differences were found in terms of specificity, PPV or NPV.

Conclusion Our results indicate that transvaginal ultrasonography is more sensitive than CA 125 in predicting myometrial invasion in endometrial cancer.

\section{INTRODUCTION}

Endometrial carcinoma is the most frequent gynecological malignancy in women ${ }^{1}$. Since 1988, the International Federation of Gynecology and Obstetrics (FIGO) has recommended surgical staging as the initial treatment in these patients in order to determine the extent of disease. This implies total abdominal hysterectomy with bilateral salpingo-oophorectomy, peritoneal cytological sampling and pelvic and periaortic lymphadenectomy ${ }^{2}$. However, complete routine staging has come under criticism in cases in which the risk of lymph node involvement is $\operatorname{low}^{3,4}$. Furthermore, it has been shown that lymphadenectomy can be safely obviated in selected cases ${ }^{5}$.

Myometrial invasion is one of the most important factors associated with lymph node metastases ${ }^{6}$. Some authors advocate perioperative gross or frozen-section evaluation for myometrial infiltration in clinical stage I endometrial cancer to aid the decision of whether lymphadenectomy should be performed or not $^{7-9}$. Frozensection evaluation has been shown to be highly accurate in determining myometrial invasion $(94 \%)^{10}$. However, it is

Correspondence: Dr J. L. Alcázar, Department of Obstetrics and Gynecology, Clínica Universitaria de Navarra, Avenida Pio XII, 36, 31008 Pamplona, Spain 
time consuming and is not performed in all hospitals. Conversely, gross evaluation has been shown to be much less accurate $^{11,12}$. Therefore, a method that could reliably assess myometrial invasion preoperatively would be advisable to provide individual tailoring of the surgical approach.

Abdominal ultrasound has been shown to predict myometrial infiltration with an acceptable degree of accuracy $^{13-15}$. The introduction of transvaginal ultrasonography (TVS) has improved this ability further ${ }^{16-18}$.

CA 125 serum levels in patients with endometrial carcinoma correlate with the extent of disease ${ }^{19}$. Several studies have shown that the higher the preoperative CA 125 levels, the higher the risk of deep myometrial invasion ${ }^{20-23}$.

The aim of the present study was to compare the diagnostic accuracy of predicting myometrial invasion by TVS and serum CA 125 levels in the preoperative evaluation of women with endometrial cancer.

\section{MATERIALS AND METHODS}

This was a prospective study designed to assess the diagnostic performance of TVS and serum CA 125 levels in predicting myometrial infiltration in the preoperative evaluation of a series of consecutive and unselected patients with endometrial carcinoma scheduled for surgical staging at our center.

According to the method of Campbell and colleagues ${ }^{24}$, it was estimated that a sample size of at least 31 patients would be required, to detect a difference of at least $20 \%$ in terms of sensitivity, specificity, positive predictive value (PPV) and negative predictive value (NPV) in a two-sided test at the $5 \%$ significant level with a power of $80 \%$.

Patients were recruited between December 1995 and March 1999. Fifty women were enrolled in the study. The patients' mean age was 60 years (SD 10.5, range 29-77 years). Out of $50,42(84 \%)$ were postmenopausal. The mean time elapsed from the menopause in postmenopausal women was 12.5 years (SD 7.9, range 1-36 years).

All patients were evaluated prior to surgery by transvaginal ultrasonography using a Philips P-700 SE machine (Philips Ultrasound, Santa Ana, CA, USA) with real-time 6.5-MHz sector electronic phased-array endovaginal probe. All examinations were performed with the woman in the lithotomy position and after she had completely voided her bladder.

After the endovaginal probe was gently inserted into the vagina, the uterus and adnexal regions were thoroughly scanned. The uterus was measured in the three orthogonal planes. From a sagittal uterine section, endometrial thickness, at the level of maximum thickness, including both endometrial layers, was measured using on-screen electronic calipers. Myometrial invasion was suspected when the myometrial-endometrial interface was ill-defined. The depth of infiltration was estimated according to the method of Weber and co-workers ${ }^{25}$ and stated as $<50 \%$ or $\geq 50 \%$ (Figures 1 and 2). Those cases in which no myometrial invasion was suspected, e.g. where the myometrialendometrial interface was well defined, were included in the group of $<50 \%$ for analysis purposes.

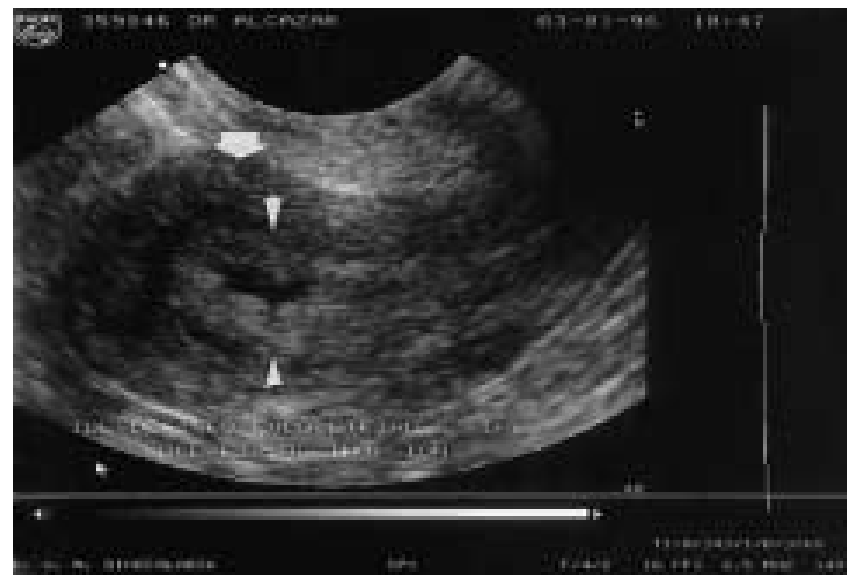

Figure 1 Transvaginal ultrasound scan in a case of a patient with endometrial cancer showing suspected deep myometrial invasion. Note the anteroposterior uterine diameter $(40 \mathrm{~mm})$ and endometrial thickness $(20 \mathrm{~mm})$

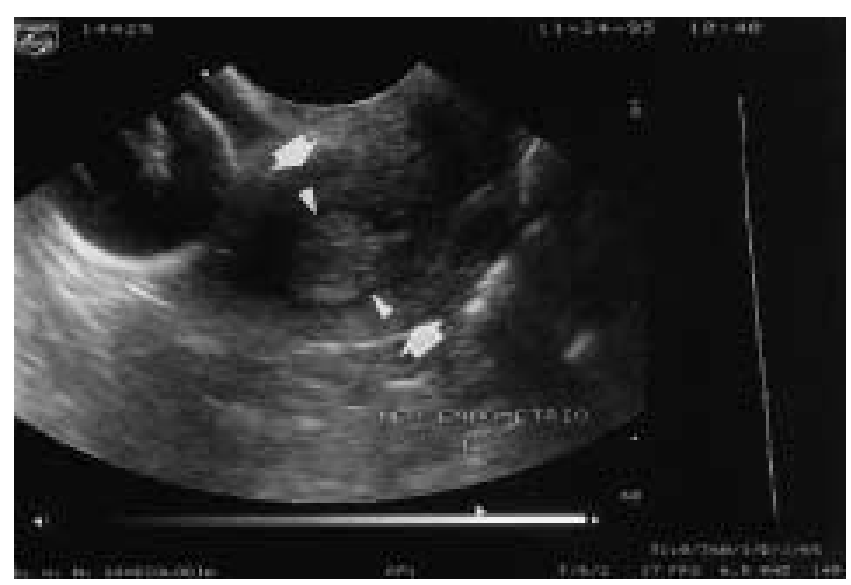

Figure 2 Transvaginal ultrasound scan in a case of a patient with endometrial cancer showing suspected superficial myometrial invasion. Note the anteroposterior uterine diameter $(43 \mathrm{~mm})$ and endometrial thickness $(8.7 \mathrm{~mm})$

All examinations were performed by one examiner (J.L.A.). Intraobserver variability for endometrial thickness was estimated by performing two measurements at $10-\mathrm{min}$ intervals in the first ten patients included, and calculating the intraclass correlation coefficient ${ }^{26}$. Intraobserver agreement for ultrasound-estimated myometrial invasion was assessed by using Cohen's kappa index $(\kappa)$. This was done by performing two different estimations of myometrial invasion in the first ten patients. The intraclass correlation coefficient for endometrial thickness was 0.97 . Agreement for myometrial invasion (no invasion or $<50 \%$ vs. $\geq 50 \%$ ) was high $(\kappa=0.78)$.

Blood samples were collected for serum CA 125 level determination on the same day as the ultrasound examination. An enzyme immunoassay with monoclonal antibody was used (Cobas-Core CA-125-II ${ }^{\mathrm{TM}}$, Laboratories Roche, Basel, Switzerland). The sensitivity was $<5 \mathrm{IU} / \mathrm{ml}$. The inter- and intra-assay coefficients of variation were $<7.5 \%$ and $<5.3 \%$, respectively. A cut-off level of $\geq 35 \mathrm{IU} / \mathrm{ml}$ was used for the suspicion of deep myometrial invasion ${ }^{21}$. 
All patients underwent surgical staging at our center within 1 week after TVS and CA 125 determination. Definitive histopathological diagnosis regarding myometrial infiltration was used as the 'gold standard'. Surgical staging was performed according to FIGO criteria $^{27}$.

The Kolmogorov-Smirnov test was used to assess the normal distribution of continuous variables. Two-tailed Student's $t$ test or the Mann-Whitney $U$ test were used to compare continuous data. Categorical variables were compared using Fisher's exact test.

Data are presented as mean with $95 \%$ confidence intervals $(\mathrm{CI})$ or median with interquartile range, according to data distribution.

Sensitivity, specificity, positive predictive value (PPV) and negative predictive value (NPV) were calculated for TVS and CA 125 and compared using the McNemar test.

Receiver operating characteristic (ROC) analysis was used to determine whether the pre-established CA 125 cut-off value was the optimal one. ROC analysis was also used to determine the best endometrial thickness cut-off value for prediction of deep myometrial invasion. The best cut-off level was chosen according to the best combination of sensitivity and false-positive rate.

A $p$ value of less than 0.05 was considered statistically significant in all tests used. All statistical analyses were performed with the SPSS 6.1 for Windows (SPSS Inc., Chicago, IL, USA) and the Epi-Info (WHO, Geneva, Switzerland) statistical packages.

\section{RESULTS}

Fifty patients with endometrial cancer were included in this study. In all patients TVS could be satisfactorily performed, serum CA 125 levels determined and surgical staging done.
Histopathology revealed deep myometrial invasion in 15 patients $(30 \%)$. In 35 women $(70 \%)$ no invasion $(n=7)$ or $<50 \%$ infiltration $(n=28)$ was found. Surgical stages were as follows: stage Ia, seven (14\%); stage Ib, 22 (44\%); stage Ic, eight (16\%); stage IIb, three $(6 \%)$; stage IIIa, four $(8 \%)$; stage IIIc, six $(12 \%)$. Histology was as follows: endometrioid adenocarcinoma, $40(80 \%)$; clear-cell carcinoma, one $(2 \%)$; papillary carcinoma, two $(4 \%)$; adenosquamous carcinoma, five $(10 \%)$; sarcoma, two $(4 \%)$.

Overall mean endometrial thickness was $15 \mathrm{~mm}$ (SD 6.9, range $3.4-30 \mathrm{~mm}$ ). The mean thickness in patients with deep infiltration was significantly higher than that with no, or $<50 \%$, invasion (Table 1 ). The median CA 125 level was $18.2 \mathrm{IU} / \mathrm{ml}$ (IQR 17.3, range 3.8-206 IU/ml). The median CA 125 level in patients with deep invasion was significantly higher than that with no, or $<50 \%$, invasion (Table 1).

Deep invasion was suspected on TVS in 15 patients $(30 \%)$ and superficial invasion (no, or $<50 \%)$ in $35(70 \%)$ (Table 2). Nine out of $50(18 \%)$ patients had a CA 125 level higher than $35 \mathrm{IU} / \mathrm{ml}$ (Table 3).

The sensitivity, specificity, PPV and NPV for TVS and CA 125 are shown in Table 4. The sensitivity for TVS was found to be significantly higher than that for CA 125 $(p=0.008)$. No significant differences were found in terms of specificity, PPV and NPV.

ROC analysis showed that the best cut-off level for endometrial thickness was $14 \mathrm{~mm}$. However, its diagnostic performance was quite low (Figure 3). ROC analysis for CA 125 indicated that the best cut-off level was $30 \mathrm{IU} / \mathrm{ml}$ with a sensitivity of $53.7 \%$ and a false-postive rate of $8.6 \%$ (specificity 91.4\%) (Figure 3). These values were not statistically different from those for TVS.

Two out of three cases of stage IIb cancer were correctly diagnosed by transvaginal ultrasound. The CA 125 values

Table 1 Endometrial thickness and CA 125 according to histopathological diagnosis of myometrial invasion (MI)

\begin{tabular}{|c|c|c|c|c|}
\hline & \multicolumn{2}{|c|}{$M I<50 \%$} & \multicolumn{2}{|c|}{$M I \geq 50 \%$} \\
\hline $\begin{array}{l}\text { Mean endometrial thickness }(\mathrm{mm})^{*} \\
\text { Median CA } 125(\mathrm{IU} / \mathrm{ml})^{\dagger}\end{array}$ & \multicolumn{2}{|c|}{$13.4(95 \%$ CI $11.2-15.7)$} & \multicolumn{2}{|c|}{$18.7(95 \%$ CI $15.0-22.3)$} \\
\hline \multicolumn{5}{|c|}{ IQR, interquartile range; *ANOVA, $p=0.014 ;{ }^{\dagger} \mathrm{U}$ test, $p=0.002$} \\
\hline \multicolumn{2}{|c|}{$\begin{array}{l}\text { Table } 2 \text { Transvaginal sonography (TVS) and histopathological } \\
\text { diagnoses of myometrial invasion (MI) }\end{array}$} & $\begin{array}{l}\text { Table } 3 \mathrm{C} \\
\text { invasion }(\mathrm{M} \\
\end{array}$ & opathologic & es of myon \\
\hline & Histopathology & & \multicolumn{2}{|c|}{ Histopathology } \\
\hline$M I<50 \%$ & $M I \geq 50 \%$ & CA 125 & $M I<50 \%$ & $M I \geq 50 \%$ \\
\hline $\begin{array}{l}\mathrm{MI}<50 \% \\
\mathrm{MI} \geq 50 \%\end{array}$ & $\begin{array}{r}2 \\
13\end{array}$ & $\begin{array}{l}<35 \mathrm{IU} / \mathrm{ml} \\
\geq 35 \mathrm{IU} / \mathrm{ml}\end{array}$ & $\begin{array}{r}32 \\
3\end{array}$ & $\begin{array}{l}9 \\
6\end{array}$ \\
\hline
\end{tabular}

Table 4 Sensitivity, specificity, positive predictive value (PPV) and negative predictive value (NPV) for transvaginal sonography (TVS) and CA 125

\begin{tabular}{lrcrc}
\hline & Sensitivity $^{*}$ & Specificity $^{\dagger}$ & $P P V^{\dagger}$ & $N^{\dagger}$ \\
\hline TVS & $86.7 \%(59.5-98.3 \%)$ & $94.3 \%(80.8-99.3 \%)$ & $86.7 \%(59.5-98.3 \%)$ & $94.3 \%(80.8-99.3 \%)$ \\
CA 125 & $40 \%(16.3-67.7 \%)$ & $91.4 \%(76.9-98.2 \%)$ & $66.7 \%(29.9-92.5 \%)$ & $78.0 \%(63.4-89.5 \%)$ \\
\hline
\end{tabular}

$* p=0.008 ;{ }^{\dagger} \mathrm{NS}$ 


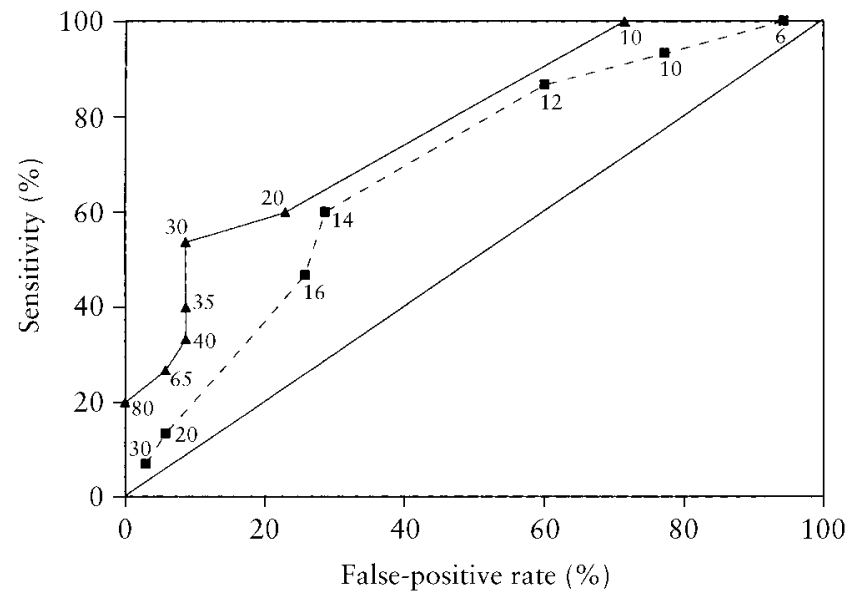

Figure 3 Receiver operating characteristic curves for CA 125 (triangles; numbers indicate cut-off values) and endometrial thickness (squares; numbers indicate endometrial thickness in millimeters)

of these cases were $41.6 \mathrm{IU} / \mathrm{ml}, 25 \mathrm{IU} / \mathrm{ml}$ and $28.8 \mathrm{IU} / \mathrm{ml}$, respectively.

\section{DISCUSSION}

Surgical staging is currently the recommended initial therapeutic approach in patients with clinical stage I endometrial carcinoma. This surgical stage requires total abdominal hysterectomy with bilateral salpingo-oophorectomy, peritoneal cytological washings and pelvic and periaortic lymphadenectomy ${ }^{2}$.

However, in some selected cases, in which the risk of lymph node involvement is low, lymphadenectomy may be unnecessary. The main criterion used to decide this approach is perioperative gross or frozen-section evaluation of myometrial invasion at the time of surgery ${ }^{7-9}$. Frozen sections have been demonstrated to be highly accurate $^{10}$. Gross evaluation accuracy, however, is limited ${ }^{11,12}$.

Accurate preoperative assessment of myometrial invasion would be useful in some clinical settings in which prolonged surgery might be contraindicated, for example in patients with obesity, cardiovascular disorders or advanced age. Preoperative assessment would allow the planning of both surgery and therapy on an individual basis.

Several imaging techniques have been evaluated to determine their diagnostic performance in predicting myometrial invasion in patients with endometrial cancer. Computerized tomography (CT) has not been shown to be useful $^{28}$. Magnetic resonance imaging (MRI) has been demonstrated to be highly accurate, with sensitivity ranging from 56 to $91 \%^{29-32}$. TVS has also been found to be accurate, with sensitivity ranging from 78 to $93 \%{ }^{16-18,25,33,34}$. Some studies have demonstrated that TVS is as accurate as MRI ${ }^{35,36}$. Although, to the best of our knowledge, no cost-benefit analysis comparing both methods has been reported, we believe that, on the basis of the costs of each technique, TVS should be performed as the first step.
CA 125 is a celomic antigen that has been found to correlate with the extent of disease in endometrial cancer ${ }^{19}$. Several studies have demonstrated that high levels are associated with deep myometrial invasion ${ }^{20-23}$. With a cut-off level of $\geq 35 \mathrm{IU} / \mathrm{ml}$, the sensitivity of detecting deep infiltration is about $50 \%{ }^{20-23}$.

In our study we have compared the diagnostic performance of TVS and CA 125 in detecting myometrial invasion in patients with endometrial cancer. Analyzed separately, our results regarding TVS are similar to those of previous studies $^{16-18,25,33,34}$, showing a high sensitivity and specificity. We had two cases of overestimation of myometrial invasion. These two cases were one stage Ia and one stage Ib in which the carcinoma arose from a large endometrial polyp. This could explain the mistake in estimation. We also had two cases of underestimation of myometrial invasion. In these cases endometrial thickness was $6.0 \mathrm{~mm}$ and $8.1 \mathrm{~mm}$, respectively.

With respect to CA 125 , our results are similar to those of previous studies ${ }^{20-23}$, resulting in high specificity but low sensitivity.

When comparing both methods, the sensitivity of TVS was significantly higher than that for CA 125 . The only previous study that compared ultrasound with CA 125 in predicting myometrial invasion was reported by Lehtovirta and co-workers ${ }^{37}$. They found that the prediction of ultrasound was superior to that of CA 125 levels. Our results confirm and support these previous results. However, if we use the best CA 125 cut-off level found on ROC analysis $(30 \mathrm{IU} / \mathrm{ml})$, there is no difference between the two methods. This finding regarding the optimal CA 125 cutoff level is in agreement with the results of a recent study reported by Kurihara and colleagues, who found that the best cut-off level for preoperatively predicting deep myometrial invasion in a series of 110 postmenopausal women with endometrial cancer was lower than $35 \mathrm{IU} / \mathrm{ml}^{38}$.

In conclusion, our results indicate that TVS is accurate in detecting deep myometrial invasion in endometrial cancer and that it is more sensitive than CA 125 when a cut-off level of $\geq 35 \mathrm{IU} / \mathrm{ml}$ is used. Our findings suggest that this cut-off value may need to be modified.

\section{REFERENCES}

1. Parker SL, Tong T, Bolden S, Wingo PA. Cancer statistics, 1996. CA Cancer J Clin 1996;46:5-27

2. DiSaia PJ, Creasman WT, eds. Clinical Gynecologic Onco$\log y, 4$ th edn. St Louis: Mosby, 1993

3. Boronow RC, Morrow CP, Creasman WT, DiSaia PJ, Silverberg SG, Miller A. Surgical staging in endometrial cancer: clinical-pathologic findings of a prospective study. Obstet Gynecol 1984;68:825-32

4. Belinson JL, Lee KR, Badger GJ, Pretorius RG, Jarrell MA. Clinical stage I adenocarcinoma of the endometrium - analysis of recurrences and the potential benefit of staging lymphadenectomy. Gynecol Oncol 1992;44:17-23

5. Bloss JD, Berman ML, Bloss LP, Buller RE. Use of vaginal hysterectomy for the management of stage I endometrial cancer in the medically compromised patient. Gynecol Oncol 1991;40:74-7 
6. Creasman WT, Morrow CP, Bundy BN, Homesley HD, Graham JE, Heller PB. Surgical pathologic spread patterns of endometrial cancer: a Gynecologic Oncology Group study. Cancer 1987;60:2035-40

7. Berman ML, Berek JS. Uterine corpus. In Haskell CM, ed. Cancer Treatment, 3rd edn. Philadelphia: Saunders, 1990: 338-51

8. Homesley HD. Management of endometrial cancer. Am J Obstet Gynecol 1996;174:529-34

9. Rose PG. Endometrial cancer. N Engl J Med 1996;335:640-9

10. Noumoff JS, Menzin A, Mikuta J, Lusk EJ, Morgan M, LiVolsi VA. The ability to evaluate prognostic variables on frozen section in hysterectomies performed for endometrial carcinoma. Gynecol Oncol 1991;42:202-8

11. Doering DL, Barnhill DR, Weiser EB, Burke TW, Woodward JE, Park RC. Intraoperative evaluation of depth of myometrial invasion in stage I endometrial adenocarcinoma. Obstet Gynecol 1989;74:930-3

12. Teefey SA, Stahl JA, Middleton WD, Huettner PC, Bernhard LM, Brown JJ, Hildebolt CF, Mutch DG. Local staging of endometrial carcinoma: comparison of transvaginal and intraoperative sonography with gross visual inspection. Am J Roentgenol 1996;166:547-52

13. Lehtovirta P, Cacciatore B, Wahlstrom T, Ylöstalo P. Ultrasonic assessment of endometrial cancer invasion. J Clin Ultrasound 1987;15:519-24

14. Fleischer AC, Dudley BS, Entman SS, Baxter JW, Kalemeris GC, James AE. Myometrial invasion by endometrial carcinoma: sonographic assessment. Radiology 1987;162:307-10

15. Cacciatore B, Lehtovirta P, Wahlström T, Ylöstalo P. Preoperative sonographic evaluation of endometrial cancer. Am J Obstet Gynecol 1989;160:133-7

16. Conte M, Guariglia L, Benedetti-Panici P, Scambia G, Cento $\mathrm{R}$, Mancuso S. Transvaginal ultrasound evaluation of myometrial invasion in endometrial carcinoma. Gynecol Obstet Invest 1990;29:224-6

17. Sahakian V, Syrop C, Turner D. Endometrial carcinoma: transvaginal ultrasonography prediction of depth of myometrial invasion. Gynecol Oncol 1991;43:217-19

18. Artner A, Bösze P, Gonda G. The value of ultrasound in preoperative assessment of the myometrial and cervical invasion in endometrial carcinoma. Gynecol Oncol 1994;54: 147-51

19. Soper JT, Berchuck A, Olt GJ, Soisson AP, Clarke-Pearson DL, Bast RC. Preoperative evaluation of serum CA 125, TAG 72 and CA $15-3$ in patients with endometrial carcinoma. Am J Obstet Gynecol 1990;163:1204-9

20. Benedetti-Panici P, Scambia G, Baiocchi G, Perrone L, Greggi S, Battaglia F, Mancuso S. Multiple serum markers in patients with endometrial cancer. Gynecol Obstet Invest 1989;27: 208-12

21. Scambia G, Gadducci A, Benedetti-Panici P, Foti E, Ferdeghini M, Ferrandina G, Amoroso M, Castellani C, Facchini V, Mancuso S. Combined used of CA 125 and CA 15-3 in patients with endometrial carcinoma. Gynecol Oncol 1994; 54:292-7

22. Takeshima N, Shimizu Y, Umezawa S, Hirai Y, Chen J-T, Fujimoto I, Yamauchi K, Hasumi K. Combined assay of serum levels of CA 125 and CA 19-9 in endometrial carcinoma. Gynecol Oncol 1994;54:321-6

23. Sood AK, Buller RE, Burger RA, Dawson JD, Sorosky JL, Berman M. Value of preoperative CA 125 level in the manage- ment of uterine cancer and the prediction of outcome. Obstet Gynecol 1997;90:441-7

24. Campbell MJ, Julious SA, Altman DG. Estimating sample sizes for binary, ordered categorical and continuous outcomes in two group comparisons. Br Med J 1995;311:1145-8

25. Weber G, Merz E, Bahlmann F, Mitze M, Weikel W, Knapstein PG. Assessment of myometrial infiltration and preoperative staging by transvaginal ultrasound in patients with endometrial carcinoma. Ultrasound Obstet Gynecol 1995;6: 362-7

26. Bland JM, Altman DG. Measurement error and correlation coefficients. Br Med J 1996;313:41-2

27. Sheperd JH. Revised FIGO staging for gynecological cancer. Br J Obstet Gynaecol 1989;96:889-92

28. Kim SH, Kim HD, Song YS, Kang SB, Lee HP. Detection of deep myometrial invasion in endometrial carcinoma: comparison of transvaginal ultrasound, CT and MRI. J Comput Assist Tomogr 1995;19:766-72

29. Belloni C, Vigano R, del Maschio A, Sironi S, Taccagni GL, Vignali M. Magnetic resonance imaging in endometrial staging. Gynecol Oncol 1990;37:172-7

30. Chen SS, Rumancik WM, Spiegel G. Magnetic resonance imaging in stage I endometrial carcinoma. Obstet Gynecol 1990;75:274-7

31. Lien HH, Blomlie V, Trope C, Kaern J, Abeler VM. Cancer of the endometrium: value of MR imaging in determining depth of invasion into myometrium. Am J Roentgenol 1991;157: $1221-3$

32. Scoutt LM, McCarthy SM, Flynn SD, Lange RC, Long F, Smith RC, Chambers SK, Kohorn E, Schwartz P, Chambers JT. Clinical stage I endometrial carcinoma: pitfalls in preoperative assessment with MR imaging. Radiology 1995;194: $567-72$

33. Prömpeler HJ, Madjar H, Du Bois A, Latterman U, Wilhelm C, Kommoss F, Pfleiderer A. Transvaginal sonography of myometrial invasion depth in endometrial cancer. Acta Obstet Gynecol Scand 1994;73:343-6

34. Gabrielli S, Marabini A, Bevini M, Linsalata I, Falco P, Milano V, Zantedeschi B, Bovicelli A, Stagnozzi R, Cacciatore B, Gubbini G, Bovicelli L. Transvaginal sonography vs hysteroscopy in the preoperative staging of endometrial carcinoma. Ultrasound Obstet Gynecol 1996;7:443-6

35. Gordon AN, Fleischer AC, Dudley BS, Drolshagan LF, Kalemeris GC, Partain CL, Jones HW, Burnett LS. Preoperative assessment of myometrial invasion of endometrial adenocarcinoma by sonography (US) and magnetic resonance imaging (MRI). Gynecol Oncol 1989;34:175-9

36. DelMaschio A, Vanzulli A, Sironi S, Spagnolo D, Belloni C, Garancini P, Taccagni GL. Estimating the depth of myometrial involvement by endometrial carcinoma: efficacy of transvaginal sonography vs MR imaging. Am J Roentgenol 1993;160:533-8

37. Lehtovirta P, Cacciatore B, Ylöstalo P. Serum CA 125 levels and sonography in the pre-operative assessment of myometrial invasion of endometrial cancer. Br J Obstet Gynaecol 1994; 101:532-5

38. Kurihara T, Mizunuma H, Obara M, Andoh K, Ibuki Y, Nishimura T. Determination of a normal level serum CA125 in postmenopausal women as a tool for preoperative evaluation and postoperative surveillance of endometrial carcinoma. Gynecol Oncol 1998;69:192-6 